\title{
Enzymological Features of Aromatic Amino Acid Biosynthesis Reflect the Phylogeny of Mycoplasmas
}

\author{
By ALAN BERRY, ${ }^{1} \dagger$ SUHAIL AHMAD,${ }^{2}$ ALAN LISS, ${ }^{1}$ AND \\ ROY A. JENSEN ${ }^{1,2 *}$ \\ ${ }^{1}$ Department of Biological Sciences, State University of New York at Binghamton, \\ Binghamton, NY 13901, USA \\ ${ }^{2}$ Department of Microbiology and Cell Science, $1059 \mathrm{McC}$ arty Hall, University of Florida, \\ Gainesville, FL 32611, USA
}

(Received 26 January 1987; revised 24 March 1987)

\begin{abstract}
Acholeplasma laidlawii possesses a biochemical pathway for tyrosine and phenylalanine biosynthesis, while Mycoplasma iowae and Mycoplasma gallinarum do not. The detection of 7phospho-2-dehydro-3-deoxy-D-arabino-heptonate (DAHP) synthase (EC 4.1.2.15), dehydroshikimate reductase (EC 1.1.1.25) and 3-enol-pyruvoylshikimate-5-phosphate synthase (EC 2.5.1.19) activities in cell-free extracts established the presence in $A$. laidlawii of a functional shikimate pathway. L-Phenylalanine synthesis occurs solely through the phenylpyruvate route via prephenate dehydratase (EC 4.2.1.51), no arogenate dehydratase activity being found. Although arogenate dehydrogenase was detected, L-tyrosine synthesis appears to occur mainly through the 4-hydroxyphenylpyruvate route, via prephenate dehydrogenase (EC 1.3.1.12), which utilized $\mathrm{NAD}^{+}$as a preferred coenzyme substrate. L-Tyrosine was found to be the key regulatory molecule governing aromatic biosynthesis. DAHP synthase was feedback inhibited by L-tyrosine, but not by L-phenylalanine or L-tryptophan; L-tyrosine was a potent feedback inhibitor of prephenate dehydrogenase and an allosteric activator of prephenate dehydratase. Chorismate mutase (EC 5.4.99.5) was sensitive to product inhibition by prephenate. Prephenate dehydratase was feedback inhibited by L-phenylalanine. It was also activated by hydrophobic amino acids (L-valine, L-isoleucine and L-methionine), similar to results previously found in a number of other genera that share the Gram-positive line of phylogenetic descent. Aromatic-pathway-encoded cistrons present in saprophytic large-genome mycoplasmas may have been eliminated in the parasitic small-genome mycoplasmas.
\end{abstract}

\section{INTRODUCTION}

Mycoplasma is the common name for cell-wall-less prokaryotes (class Mollicutes). The size of the mycoplasma genome approaches what is considered to be the minimal coding capacity for cell function (Razin, 1985). While significant advances have been made in mycoplasma taxonomy and membrane research, progress in the study of mycoplasma metabolism has been slow, owing primarily to the complex growth requirements of these organisms (Razin, 1985). The best-studied biochemical pathways in mycoplasmas are catabolic pathways of energy production (Pollack et al., 1983) and lipid biosynthesis (Smith, 1971). Little is known about the ability of mycoplasmas to synthesize amino acids.

$\dagger$ Present address: Department of Microbiology and Immunology, University of Illinois Health Sciences Center at Chicago, Chicago, IL 60612, USA.

Abbreviations: DAHP, 7-phospho-2-dehydro-3-deoxy-D-arabino-heptonate; E4P, D-erythrose 4-phosphate; PEP, phosphoenolpyruvate; EPSP, 3-enol-pyruvoylshikimate-5-phosphate; OPA, o-phthalaldehyde. 
Several groups have reported that mycoplasmas appear to possess an intact pathway for the biosynthesis of aromatic amino acids (Rodwell \& Mitchell, 1979; Smith, 1971), based upon the use of Acholeplasma laidlawii, the least fastidious mycoplasma species. Thus, $A$. laidlawii did not require L-phenylalanine and L-tyrosine for growth (provided that $\mathrm{L}$-alanine was supplied), and ${ }^{14} \mathrm{C}$-labelled shikimic acid was incorporated into protein. Mycoplasma mycoides strain $\mathrm{Y}$, for which completely defined media are available, requires both L-phenylalanine and L-tyrosine (Rodwell \& Mitchell, 1979).

We addressed the following questions. (1) Would direct enzymological analysis verify the presence of an intact aromatic amino acid biosynthetic pathway in mycoplasmas? (2) Does the curious finding that $L$-alanine relieves the growth requirement for $L$-phenylalanine and $L$ tyrosine in $A$. laidlawii indicate some kind of role for $\mathrm{L}$-alanine in the regulation of $\mathrm{L}$ phenylalanine and L-tyrosine synthesis? (3) What enzymological features of aromatic amino acid biosynthesis in mycoplasmas are shared with the phylogenetically-near Gram-positive eubacteria (Razin, 1985)? The latter question arises from the contention (Jensen, 1985) that the evolution of biochemical pathways in prokaryotes can be traced backward provided that a suitable phylogenetic tree is available to guide the selection of organisms for study. Current dogma indicates that the mycoplasmas arose as an evolutionary branch of the low $\mathrm{G}+\mathrm{C}$ Grampositive eubacterial (Bacillus-Lactobacillus-Clostridium-Streptococcus) line of descent, based on oligonucleotide cataloguing of 16S rRNA (Fox et al., 1980; Woese et al., 1980), 5S rRNA sequencing (Rogers et al., 1985), and comparative enzyme-immunological studies (Neimark \& London, 1982).

\section{METHODS}

Strains and growth conditions. Mycoplasma iowae and Mycoplasma gallinarum were type strains from the collection of Julius Fabricant (Cornell University, Ithaca, NY, USA). Two colonial variants of Acholeplasma laidlawii JA1 (Jcct and Jgct) used in this study were described by Liss \& Ritter (1985). A. laidlawii cultures were grown in tryptose liquid medium supplemented with $1 \%$ (v/v) PPLO serum fraction (Difco) (Maniloff, 1969). Solid medium was prepared by adding $10 \mathrm{~g}$ Bacto agar (Difco) to the Part 1 recipe component (Maniloff, 1969) prior to autoclaving. Medium used to propagate the two Mycoplasma species was as specified above, but supplemented with $10 \%(\mathrm{v} / \mathrm{v})$ heat-inactivated donor horse serum (KC Biologicals). All cultures were incubated at $35^{\circ} \mathrm{C}$ in air without shaking. Cells collected by centrifugation from liquid medium were pooled and suspended in 5-10 $\mathrm{ml}$ medium to obtain a sufficient cell mass for extract preparation and were either used immediately or stored at $-80^{\circ} \mathrm{C}$.

Preparation of extracts. Crude cell-free extracts were prepared either by sonication or by $\mathrm{pH} / \mathrm{osmotic}$-shock lysis of thawed cell suspensions. Extracts used for all assays [except 7-phospho-2-dehydro-3-deoxy-D-arabino-heptonate (DAHP) synthase and prephenate dehydratase] were prepared by centrifuging $5-10 \mathrm{ml}$ cell suspension and resuspending the cell pellet in $5 \mathrm{ml}$ ice-cold $50 \mathrm{~mm}$-Tris/ $\mathrm{HCl}$ (pH 7.5) containing $1.0 \mathrm{mM}$-dithiothreitol (DTT) and $1.0 \mathrm{mM}$ EDTA (buffer A). Sonication was carried out at $4^{\circ} \mathrm{C}$ using a Lab-line Ultratip sonication system and applying one $15 \mathrm{~s}$ burst of energy at an intensity of $100-110 \mathrm{mV}$. Cell debris was removed by ultracentrifugation at $150000 \mathrm{~g}$ for $1 \mathrm{~h}$ at $4^{\circ} \mathrm{C}$. The resulting supernatant was used directly for enzyme assays. For prephenate dehydratase assays, extracts were prepared by mixing $6.0 \mathrm{ml}$ thawed cell suspension with $2.5 \mathrm{ml} 20 \mathrm{mM}-\mathrm{Tris} / \mathrm{HCl}$ containing $1.0 \mathrm{mM}$-DTT and $1.0 \mathrm{mM}$-EDTA at pH 7.5 , followed by sonication and ultracentrifugation as described above. The resulting supernatant was desalted by passage through a prepacked Sephadex G-25 column, using buffer $A$ as the equilibration and elution buffer. The final desalted extract (about $12 \mathrm{ml}$ ) was then concentrated to $5.5 \mathrm{ml}$ by ultrafiltration (PM-10 membrane, Amicon) before use. Extracts used for DAHP synthase assays were prepared by $\mathrm{pH} / \mathrm{osmotic}$-shock lysis. A $6 \mathrm{ml}$ volume of thawed cell suspension was mixed with $3 \mathrm{ml} 20 \mathrm{mM}$ potassium phosphate buffer $\mathrm{pH} 6.5$, containing $1.0 \mathrm{mM} \mathrm{DTT}$, and held at $25^{\circ} \mathrm{C}$ for $20 \mathrm{~min}$. Cell debris was removed by ultracentrifugation (as above), and the resulting supernatant was desalted using prepacked Sephadex G-25 columns. The equilibration and elution buffer was 50 mM-potassium phosphate $\mathrm{pH} 7.0$, containing $1.0 \mathrm{mM}$ DTT (buffer B).

Enzyme assays. Appropriate controls were included in all assays to account for possible interference by reaction mixture components, and care was taken to ensure that reaction velocities were linear with respect to the variables of protein concentration and elapsed reaction time. The PPLO serum fraction used for growth was screened for enzymic activities to confirm that any activities detected did not originate from the serum fraction. All reactions were run at $37^{\circ} \mathrm{C}$, and the standard time was $20 \mathrm{~min}$ (except for the continuous arogenate dehydrogenase and prephenate dehydrogenase assays). 
DAHP synthase (EC 4.1 2.15) was assayed using the method of Srinivasan \& Sprinson (1959) as modified by Jensen \& Nester (1966). Standard reaction mixtures contained buffer B, 1.0 mM-D-erythrose 4-phosphate (E4P), $1.0 \mathrm{mM}$-phosphoenolpyruvate (PEP), and enzyme in a final volume of $0.2 \mathrm{ml}$. Dehydroshikimate reductase (EC 1.1.1.25) was assayed in the reverse direction (as shikimate dehydrogenase activity) by following the continuous formation of NADPH resulting from the NADP+-dependent oxidation of shikimate to dehydroshikimate. Reaction mixtures $(0.2 \mathrm{ml})$ contained buffer A, $0.5 \mathrm{mM}-\mathrm{NADP}^{+}, 1.0 \mathrm{mM}$-shikimic acid, and enzyme. Cofactor reduction was monitored using an Aminco-Bowman spectrophotofluorometer (excitation at $340 \mathrm{~nm}$, emission at $460 \mathrm{~nm}$ ). Activity was quantified by relating fluorescence to a standard curve constructed using authentic NADPH. 3-enol-pyruvoylshikimate-5-phosphate (EPSP) synthase (EC 2.5.1.19) was assayed as described by Rubin et al. (1984). Reaction mixtures ( $0.2 \mathrm{ml})$ contained buffer A, 3.0 mM-shikimate 3-phosphate, 3.0 mM-PEP, $2.0 \mathrm{mM}-\mathrm{NaMoO}_{2} .2 \mathrm{H}_{2} \mathrm{O}$, and enzyme. Chorismate mutase (EC 5.4.99.5) and prephenate dehydratase (EC 4.2.1.51) were assayed as outlined by Patel $e t$ al. (1977). Standard reaction mixtures for both assays contained buffer A, a $1.0 \mathrm{~mm}$ final concentration of the appropriate substrate, and enzyme in a final volume of $0.2 \mathrm{ml}$. Arogenate dehydratase was assayed using the high performance liquid chromatography (HPLC) method described by Zamir et al. (1985). Buffer B was used for arogenate dehydratase assays to minimize interference in the detection of $o$-phthalaldehyde (OPA) derivatives by Tris/ $\mathrm{HCl}$. Reaction mixtures contained buffer B, $1.7 \mathrm{mM}-\mathrm{L}$ arogenate, and enzyme in a final volume of $0.2 \mathrm{ml}$, and reactions were allowed to proceed for $60 \mathrm{~min}$ prior to OPA derivatization and HPLC analysis. Prephenate dehydrogenase (EC 1.3.1.12) and arogenate dehydrogenase assays were carried out as described by Patel et al. (1977). Standard reaction mixtures ( $0.2 \mathrm{ml})$ contained buffer A, a $1.0 \mathrm{~mm}$ final concentration of substrate, $0.5 \mathrm{~mm} \mathrm{NAD}{ }^{+}$or NADP ${ }^{+}$, and enzyme. Protein concentrations were measured according to the method of Bradford (1976), using bovine serum albumin as the reference protein.

Enzyme data obtained showing inhibition or activation should be treated as indicative rather than definitive, since crude, unfractionated extract preparations were used. However, appropriate controls to confirm directly the formation of product were carried out (e.g. HPLC measurement of phenylpyruvate otherwise estimated as absorbance at $320 \mathrm{~nm}$ in the prephenate dehydratase reaction).

Materials. Unless indicated otherwise, all biochemicals and commercially-prepared enzymes were obtained from Sigma. L-Arogenate was prepared according to Zamir et al. (1983). Barium prephenate was isolated from culture supernatants of a tyrosine auxotroph of Salmonella typhimurium (Dayan \& Sprinson, 1970), and was converted to the potassium salt with excess $\mathrm{K}_{2} \mathrm{SO}_{4}$ prior to use. Chorismate, isolated from the accumulation medium of the triple auxotroph of Klebsiella pneumoniae 62-1, was purified as the free acid (Gibson, 1970). Shikimate 3-phosphate was prepared according to Knowles \& Sprinson (1970), except that it was converted to a tetramethylammonium salt. Analytical-grade glyphosate [ $N$-(phosphonomethyl)glycine], used as an inhibitor of EPSP synthase, was a gift from Monsanto Chemical Co. Protein assay reagent was obtained from Bio-Rad and prepacked Sephadex G-25 columns (PD10) from Pharmacia. All other chemicals were purchased from commercial sources and were standard reagent-grade.

\section{RESULTS}

\section{Activities of aromatic-pathway enzymes in A. laidlawii}

Table 1 shows the specific activities of key enzymes of aromatic amino acid biosynthesis in $A$. laidlawii variant Jgct. Similar results were obtained for variant Jcct. DAHP synthase activity was not found in initial experiments (Table 1), but it was successfully assayed in extracts prepared by $\mathrm{pH} /$ osmotic-shock lysis (see Table 2 ). Two other enzymes contained within the common trunk of the aromatic amino acid pathway, dehydroshikimate reductase and EPSP synthase, were also found (Table 1). EPSP synthase has been studied intensively because of its sensitivity to the broad-spectrum herbicide glyphosate (Steinrücken \& Amrhein, 1980). (All EPSP synthases studied to date are naturally sensitive to glyphosate, and we found that the $A$. laidlawii enzyme is no exception.) Under standard assay conditions, EPSP synthase activities from $A$. laidlawii strains Jcct and Jgct were inhibited $50 \%$ and $48 \%$, respectively, by $2.0 \mathrm{~mm}$ glyphosate (data not shown). Chrorismate mutase was readily detected.

Prephenate dehydratase, but not arogenate dehydratase, was found, indicating that phenylalanine synthesis occurs solely via the phenylpyruvate route (i.e. through the actions of prephenate dehydratase and phenylpyruvate aminotransferase). A. laidlawii possessed prephenate dehydrogenase activity, which exhibited a preference for $\mathrm{NAD}^{+}$as coenzyme substrate, although NADP ${ }^{+}$was also accepted. The enzyme is probably a cyclohexadienyl-type of dehydrogenase that is able to recognize L-arogenate as an alternative, less-preferred substrate. 
Table 1. Specific activities of aromatic-pathway enzymes in extracts of A. laidlawii strain Jgct

Prephenate dehydrogenase and arogenate dehydrogenase were tested using either $\mathrm{NAD}^{+}$or $\mathrm{NADP}^{+}$as cofactor.

\section{Enzyme}

DAHP synthase

Dehydroshikimate reductase

EPSP synthase

Chorismate mutase

Prephenate dehydratase

Prephenate dehydrogenase : NAD ${ }^{+}$

NADP $^{+}$

Arogenate dehydrogenase : NAD ${ }^{+}$

NADP+

Arogenate dehydratase
Specific activity

$\begin{gathered}\text { Specific activity } \\ \text { [nmol min }\end{gathered}$ (mg protein) $^{-1}$ at $37^{\circ} \mathrm{C}$ ]
(see Table 2)
1.2
47.1
58.9
1.9
1.6
0.5
0.4
ND
ND

ND, Not detected.

Table 2. Effect of aromatic-pathway endproducts and intermediates on DAHP synthase activity from A. laidlawii strain Jcct

$\begin{array}{lccc}\text { Effector } & \begin{array}{c}\text { Effector } \\ \text { concn } \ldots\end{array} & 0.1 \mathrm{mM} & 0.5 \mathrm{mM} \\ \text { L-Phenylalanine } & & 0 & 0 \\ \text { L-Tyrosine } & 42.3 & 43.0 \\ \text { L-Tryptophan } & & 0.5 & +22.6 \\ \text { Chorismate } & 0 & 0 \\ \text { Prephenate } & & 0 & 0 \\ \text { Aromatic amino acids } \dagger & & 33.2 & 40 \cdot 1\end{array}$

\footnotetext{
* Percentage inhibition is based on activity measured in the presence of effectors compared to control assays run in the absence of effectors. Specific activity of the uninhibited control $=9.7 \mathrm{nmol} \mathrm{min} \mathrm{m}^{-1}\left(\mathrm{mg}\right.$ protein) ${ }^{-1} ;+$ indicates activation.

$\dagger$ Refers to the combination of all three aromatic amino acids, each at $0.1 \mathrm{~mm}$ or $0.5 \mathrm{~mm}$ as indicated.
}

Judging from the ratio of prephenate dehydrogenase activities with $\mathrm{NAD}^{+}$and $\mathrm{NADP}^{+}$, activity with the arogenate: NADP combination would be below the detection level.

No activities of aromatic-pathway enzymes were detected in crude extracts prepared from $M$. iowae and $M$. gallinarum, regardless of whether the cells were disrupted by sonication or by $\mathrm{pH} /$ osmotic-shock lysis (data not shown).

\section{Allosteric control of aromatic biosynthesis in A. laidlawii}

$D A H P$ synthase. DAHP synthase enzymes in nature are known to be feedback inhibited by aromatic amino acids or by the midpathway intermediates, chorismate or prephenate. Table 2 shows the results of DAHP synthase assays carried out at saturating substrate concentrations in the presence of potential allosteric metabolites. L-Tyrosine at $0.1 \mathrm{~mm}$ produced $42 \%$ inhibition. Although the enzyme was reasonably sensitive, the extent of inhibition was incomplete and $0.5 \mathrm{mM}$-L-tyrosine was no more effective than $0.1 \mathrm{mM}-\mathrm{L}$-tyrosine (Fig. 1). Furthermore, the degree of L-tyrosine inhibition of DAHP synthase did not increase when the concentrations of substrates (E4P and PEP) were reduced from $1.0 \mathrm{mM}$ to $0.5 \mathrm{~mm}$ each (data not shown). The residual, uninhibited activity could prove to be due to the presence of a second allosterically insensitive isoenzyme similar to the DS-O isoenzyme in Superfamily B of the purple bacteria (Ahmad et al., 1986). Aromatic amino acids were tested in combination to detect possible synergistic effects, but none was found. The exact pattern of allosteric effects upon DAHP synthase (inhibition by L-tyrosine, activation by L-tryptophan) has no precedent within the literature (which documents considerable diversity for patterns of allosteric control for DAHP synthase). Chorismate and prephenate were not inhibitory. L-Alanine had no effect on the 


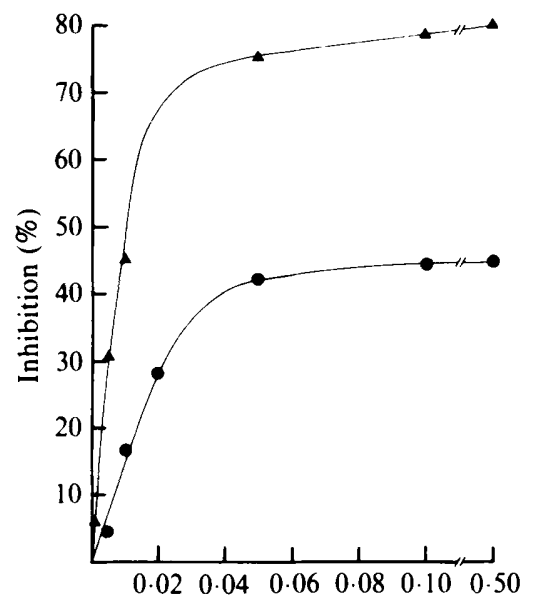

L-Phenylalanine or L-tyrosine concn (mM)

Fig. 1

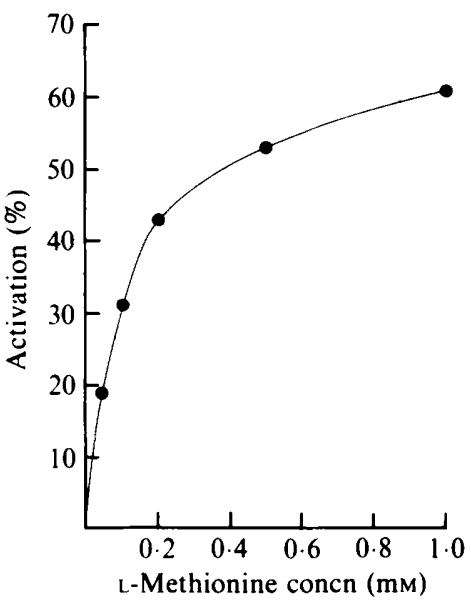

Fig. 2

Fig. 1. Inhibition of DAHP synthase activity by L-tyrosine (O), and of prephenate dehydratase activity by L-phenylalanine ( $\boldsymbol{A}$ ). The enzyme activities obtained in the absence of effector molecules were taken as reference activities for calculation of percentage inhibition values. Specific activities of the uninhibited controls are given in the Tables. Assays were performed using the standard reaction mixtures described in Methods.

Fig. 2. Activation of prephenate dehydratase from $A$. laidlawii Jcct by L-methionine. The enzyme activity obtained in the absence of methionine (Table 3 ) was taken as the reference activity for calculation of percentage activation values. Assays were performed using the standard reaction mixture described in Methods.

DAHP synthase activity (data not shown). In contrast to DAHP synthases from many Gramnegative bacteria (Jensen, 1985), the activity from $A$. laidlawii was not stimulated by divalent cations $\left(\mathrm{Mg}^{2+}, \mathrm{Co}^{2+}, \mathrm{Mn}^{2+}\right)$. Neither monovalent cations $\left(\mathrm{K}^{+}, \mathrm{Na}^{+}\right)$, nor anions $\left(\mathrm{Cl}^{-}, \mathrm{SO}_{4}^{2-}\right.$, $\mathrm{PO}_{4}^{3-}$ ) affected the activity. DAHP synthase activity was, however, slightly activated by $\mathrm{NH}_{4}^{+}$: the maximum level of activation observed was $17 \%$ at a final $\mathrm{NH}_{4} \mathrm{Cl}$ concentration of $25 \mathrm{mM}$ (data not shown).

Chorismate mutase. Chorismate mutase from A. laidlawii strains Jcct and Jgct was not subject to allosteric control by any of the aromatic amino acids or by L-arogenate. It was, however, product-inhibited by prephenate (approximately $30 \%$ inhibition by $0.5 \mathrm{~mm}$-prephenate, using the standard assay conditions).

Prephenate dehydratase. Table 3 shows the effect upon prephenate dehydratase from $A$. laidlawii strain Jcct, of aromatic endproducts and of non-aromatic metabolites known to affect prephenate dehydratase in B. subtilis (Rebello \& Jensen, 1970). L-Phenylalanine was a potent feedback inhibitor of prephenate dehydratase (Fig. 1). Under standard assay conditions $12 \mu \mathrm{M}-$ L-phenylalanine produced $50 \%$ inhibition. Both L-tyrosine and L-tryptophan stimulated prephenate dehydratase activity, and appeared to antagonize the inhibitory effect of Lphenylalanine (data not shown). The non-aromatic hydrophobic amino acids, L-valine and Lisoleucine, stimulated prephenate dehydratase activity, while L-leucine had no effect. LMethionine activated prephenate dehydratase the most (Table 3 ), $62 \%$ activation being reached at a final $\mathrm{L}$-methionine concentration of $1.0 \mathrm{mM}$ (Fig. 2).

Prephenate dehydrogenase and arogenate dehydrogenase. Activities of the tyrosine biosynthetic dehydrogenases from both $A$. laidlawii variants were tested for feedback inhibition by L-tyrosine when either $\mathrm{NAD}^{+}$or NADP ${ }^{+}$was used as a coenzyme substrate. Prephenate dehydrogenase was strongly inhibited $(85 \%)$ by $0.5 \mathrm{mM}-\mathrm{L}$-tyrosine under standard assay conditions when $\mathrm{NAD}^{+}$ 
Table 3. Effect of aromatic amino acids and remote effectors on prephenate dehydratase activity from A. laidlawii Jcct

\begin{tabular}{|c|c|c|c|c|}
\hline \multirow[b]{2}{*}{ Effector* } & \multirow{2}{*}{$\begin{array}{l}\text { Effector } \\
\text { concn ... }\end{array}$} & \multicolumn{3}{|c|}{ Percentage inhibition or activation $\dagger$} \\
\hline & & $0.1 \mathrm{~mm}$ & $0.5 \mathrm{~mm}$ & $1.0 \mathrm{~mm}$ \\
\hline Phe & & 78 & 80 & \\
\hline Tyr & & 0 & +10 & +21 \\
\hline Trp & & 0 & +5 & +17 \\
\hline Val & & 0 & +11 & \\
\hline Leu & & 0 & 0 & \\
\hline Ile & & +2 & +25 & +33 \\
\hline Met & & +31 & +53 & +61 \\
\hline
\end{tabular}

* All amino acids used were the L-isomers.

+ Percentage inhibition or activation (denoted by + ) was determined by comparing activities observed in the presence of effectors with controls run in the absence of effectors. Specific activity of uninhibited control $=3.3 \mathrm{nmol} \mathrm{min}^{-1}(\mathrm{mg} \text { protein })^{-1}$. Assays were conducted using the standard reaction mixtures described in Methods.

was used. When NADP+ was used, the degree of inhibition of prephenate dehydrogenase by Ltyrosine was significantly less $(20 \%)$. The $\mathrm{NAD}^{+}$-linked arogenate dehydrogenase activity was completely inhibited by $0.5 \mathrm{~mm}$-L-tyrosine.

\section{DISCUSSION}

\section{Routes and regulation of aromatic amino acid biosynthesis in mycoplasmas}

A. laidlawii possesses all of the metabolic machinery necessary to synthesize L-phenylalanine and L-tyrosine from the initial precursors, E4P and PEP. The allosteric properties of aromaticpathway enzymes in A. laidlawii are consistent with the maintenance of balanced intracellular levels of aromatic endproducts. Both the tyrosine and phenylalanine branches are tightly controlled by feedback inhibition in A. laidlawii. L-Tyrosine is the sole inhibitor of the earlypathway step (DAHP synthase) and can potentially enhance L-phenylalanine synthesis through direct activation of prephenate dehydratase (in addition to increasing the level of prephenate available to prephenate dehydratase following potent feedback inhibition of prephenate dehydrogenase).

The allosteric control of prephenate dehydratase by remote effectors (i.e. effectors not formed by the aromatic amino acid pathway) has been described before in a number of Grampositive prokaryotes. This phenomenon of extra-pathway regulation, termed metabolic interlock (Jensen, 1969), has been extensively studied in Bacillus subtilis, where prephenate dehydratase is subject to allosteric control by remote effectors (Rebello \& Jensen, 1970). It was postulated (Pierson \& Jensen, 1974) that in B. subtilis, the regulation of prephenate dehydratase by remote effectors was a mechanism for balancing the levels of hydrophobic amino acids within the intracellular pool in order to optimize the process of protein synthesis.

It was additionally shown that the positive and negative allosteric effectors of prephenate dehydratase in $B$. subtilis modulate the enzyme activity by mediating interconversions between active and inactive molecular-mass forms (Pierson \& Jensen, 1974; Riepl \& Glover, 1979). It is not known at present whether the $A$. laidlawii prephenate dehydratase undergoes similar molecular-mass transitions in response to allosteric effectors. However, given the phylogenetic proximity of the mycoplasmas and Bacillus (discussed below), this possibility seems likely.

\section{Significance of aromatic amino acid biosynthesis in mycoplasmas}

The size of the Acholeplasma genome (about $1000 \mathrm{MDa}$ ) is roughly twice that of the smallest mycoplasma genomes (Razin, 1985). In view of the proposal (Razin, 1985) that mycoplasma evolution is moving in the direction of genome reduction, it is suggestive that none of the enzyme 
activities of the aromatic biosynthetic pathway assayed was detected in $M$. iowae and $M$. gallinarum, both small-genome mycoplasmas : this presumably reflects the loss of a portion of the original ancestral mycoplasma genome.

\section{Metabolic relationship between $\mathrm{L}$-alanine and aromatic amino acids}

A biochemical explanation for the observation that nutritional independence for aromatic amino acids depends upon the presence of L-alanine in $A$. laidlawii (Rodwell \& Mitchell, 1979) has not yet been made. L-Alanine did not activate any of the aromatic-pathway enzymes examined. Although our analysis has not been exhaustive, most key pathway enzymes that might be suspected as targets of inhibition (e.g. prephenate dehydratase) were studied. Perhaps L-alanine (through pyruvate) allows generation of sufficient PEP for aromatic amino acid biosynthesis. Another possibility is a phenomenon of metabolite toxicity, e.g. perhaps some intermediate(s) of aromatic biosynthesis inhibit(s) L-alanine biosynthesis. Such metabolite toxicities are not uncommon (Conrad et al., 1976).

\section{Biochemical-pathway evolution and the mycoplasma genealogy}

Jensen (1985) showed that the evolution of the aromatic amino acid pathway in prokaryotes traced backward, by systematically comparing enzymic construction and allosteric control patterns in organisms that have been ordered on a well-defined phylogenetic tree established by modern sequencing techniques (Fox et al., 1980; Stackebrandt \& Woese, 1981). The mycoplasmas are part of a well-defined phylogenetic cluster that comprises one of the major sublines of the low $G+C$ Gram-positive eubacterial lineage, one which contains the contemporary Bacillus genus. Prephenate dehydratase from $B$. subtilis is feedback-inhibited by L-phenylalanine. Remote effectors are L-tryptophan (inhibitor) and L-methionine, L-leucine and prephenate (activator molecules) (Jensen, 1969; Pierson \& Jensen, 1974; Rebello \& Jensen, 1970; Riepl \& Glover, 1979). In the light of the phylogenetic proximity of the mycoplasmas and Bacillus, it is striking that prephenate dehydratase from $A$. laidlawii exhibits allosteric activation by remote effectors such as L-methionine. Since the mycoplasmas branched off from the Grampositive eubacterial lineage at a deep phylogenetic position, it follows that the regulation of prephenate dehydratase by remote effectors was probably a characteristic of an ancestral forerunner of the entire Gram-positive lineage. This possibility is strengthened further by the knowledge that the Gram-positive coryneform bacteria represent yet another major assemblage that also possesses prephenate dehydratase molecules subject to activation by hydrophobic remote effectors (Fazel \& Jensen, 1980).

While the regulation of prephenate dehydratase by remote effectors appears to be a character state that is conserved at a very deep hierarchical level in the Gram-positive lineage of eubacteria, the pattern of allosteric control for DAHP synthase in this phylogenetic group is conserved at much more shallow hierarchical levels. Thus, in $A$. laidlawii L-tyrosine is the major effector of DAHP synthase. In Bacillus DAHP synthase is feedback-inhibited by chorismate and prephenate through a mechanism of sequential feedback inhibition (Jensen \& Nester, 1965). In clostridial species, DAHP synthase is feedback-inhibited by L-phenylalanine (Jensen \& Twarog, 1972). In coryneform bacteria DAHP synthase is synergistically controlled by the combination of L-tyrosine and L-phenylalanine (Fazel et al., 1980).

These studies were supported by NSF grant DMB-8316275.

\section{REFERENCES}

Ahmad, S., Rightmire, B. \& Jensen, R. A. (1986). Evolution of the regulatory isozymes of 3-deoxy-Darabino-heptulosonate 7-phosphate synthase present in the Escherichia coli genealogy. Journal of Bacteriology 165, 146-154.

BRADFORD, M. M. (1976). A rapid and sensitive method for the quantitation of microgram quantities of protein utilizing the principle of protein-dye binding. Analytical Biochemistry 72, 248-254.
Conrad, R. A., Sokatch, J. R. \& Jensen, R. A. (1976). Relationships of metabolite inhibition of growth to flow-of-carbon patterns in nature. Life Sciences 19, 299-320.

Dayan, J. \& Sprinson, D. B. (1970). Preparation of prephenic acid. Methods in Enzymology 17A, 559561 .

FAZEL, A. M. \& Jensen, R. A. (1980). Regulation of prephenate dehydratase in coryneform species of 
bacteria by L-phenylalanine and by remote effectors. Archives of Biochemistry and Biophysics 200, 165-176.

Fazel, A. M., Bowen, J. R. \& Jensen, R. A. (1980). Arogenate (pretyrosine) is an obligatory intermediate of L-tyrosine biosynthesis: confirmation in a microbial mutant. Proceedings of the National Academy of Sciences of the United States of America 77, 1270-1273.

Fox, G. E., Stackebrandt, E., Hespell, R. B., Gibson, J., Maniloff, J., Dyer, T. A., Wolfe, R. S., Balch, W. E., Tanner, R. S., Magrum, L. J., ZABlen, L. B., Blakemore, R., Gupta, R., Bonen, L., Lewis, B. J., Stahl, D. A., Luehrsen, K. R., Chen, K. N. \& Woese, C. R. (1980). The phylogeny of prokaryotes. Science 209, 457-463.

Gibson, F. (1970). Preparation of chorismic acid. Methods in Enzymology 17A, 362-364.

JENSEN, R. A. (1969). Metabolic interlock. Regulatory interactions exerted between biochemical pathways. Journal of Biological Chemistry 244, 2816-2823.

JENSEN, R. A. (1985). Biochemical pathways in prokaryotes can be traced backward through evolutionary time. Molecular Biology and Evolution 2, 92108.

Jensen, R. A. \& Nester, E. W. (1965). The regulatory significance of intermediary metabolites: control of aromatic acid biosynthesis by feedback inhibition in Bacillus subtilis. Journal of Molecular Biology 12, 468481.

Jensen, R. A. \& Nester, E. W. (1966). Regulatory enzymes of aromatic amino acid biosynthesis in Bacillus subtilis. 1. Purification and properties of 3deoxy-D-arabino-heptulosonate 7-phosphate synthase. Journal of Biological Chemistry 241, 3365-3372.

Jensen, R. A. \& TWAROG, R. (1972). Allostery of 3deoxy-D-arabino-heptulosonate 7-phosphate synthetase in Clostridium: another conserved generic characteristic. Journal of Bacteriology 111, 641-648.

KNOWLES, P. F. \& SPRINSON, D. B. (1970). Preparation of shikimate 5-phosphate. Methods in Enzymology 17A, 351-352.

LISS, A. \& RITTER, B. E. (1985). Acholeplasma laidlawii cells acutely and chronically infected with group I acholeplasmavirus. Journal of General Microbiology 131, 1713-1718.

MANiLOFF, J. (1969). Use of blood agar plates to study Mycoplasma physiology. Microbios 1, 125-135.

NeimaRK, H. \& London, J. (1982). Origins of the mycoplasmas: sterol non-requiring mycoplasmas evolved from streptococci. Journal of Bacteriology 150, 1259-1 265.

Patel, N., Pierson, D. L. \& Jensen, R. A. (1977). Dual enzymatic routes to L-tyrosine and L-phenylalanine via pretyrosine in Pseudomonas aeruginosa. Journal of Biological Chemistry 252, 5839-5846.

Pierson, D. L. \& Jensen, R. A. (1974). Metabolic interlock: control of an interconvertible prephenate dehydratase by hydrophobic amino acids in Bacillus subtilis. Journal of Molecular Biology 90, 563-579.
Pollack, J. D., Tyron, V. V. \& Beaman, K. D. (1983). The metabolic pathways of Acholeplasma and Mycoplasma: an overview. Yale Journal of Biology and Medicine 56, 709-716.

RAZIN, S. (1985). Molecular biology and genetics of mycoplasmas (Mollicutes). Microbiological Reviews 49, 419-455.

Rebello, J. L. \& Jensen, R. A. (1970). Metabolic interlock. The multi-metabolite control of prephenate dehydratase activity in Bacillus subtilis. Journal of Biological Chemistry 245, 3738-3744.

RIEPL, R. G. \& GLover, G. I. (1979). Regulation and state of aggregation of Bacillus subtilis prephenate dehydratase in the presence of allosteric effectors. Journal of Biological Chemistry 254, 10321-10328.

Rodwell, A. W. \& Mitchell, A. (1979). Nutrition, growth, and reproduction. In The Mycoplasmas, vol. I, pp. 103-109. Edited by M. F. Barile \& S. Razin. New York: Academic Press.

Rogers, M. J., Simmons, J., Walker, R. T., WeisBURG, W. G., WOESE, C. R., TANNER, R. S., Robinson, I. M., Stahl, D. A., Olsen, G., Leach, R. H. \& ManilofF, J. (1985). Construction of the mycoplasma evolutionary tree from 5S rRNA sequence data. Proceedings of the National Academy of Sciences of the United States of America 82, 1160 1164.

Rubin, J. L., Gaines, C. G. \& Jensen, R. A. (1984). Glyphosate inhibition of 5-enolpyruvylshikimate 3phosphate synthase from suspension-cultured cells of Nicotiana silvestris. Plant Physiology 75, 839-845.

Smith, P. F. (1971). Lipids. In The Biology of Mycoplasmas, pp. 114-124. New York: Academic Press.

SRINIVASAN, P. R. \& SPRINSON, D. B. (1959). 2-Keto-3deoxy-D-arabo-heptonic acid 7-phosphate synthetase. Journal of Biological Chemistry 234, 716-722.

Stackebrandt, E. \& Woese, C. R. (1981). The evolution of prokaryotes. Symposia of the Society for General Microbiology 32, 1-32.

SteInRÜCKEN, H. C. \& AMrheIN, N. (1980). The herbicide glyphosate is a potent inhibitor of 5enolpyruvylshikimic acid-3-phosphate synthase. Biochemical and Biophysical Research Communications 94, 1207-1212.

Woese, C. R., Maniloff, J. \& Zablen, L. B. (1980). Phylogenetic analysis of the mycoplasmas. Proceedings of the National Academy of Sciences of the United States of America 77, 494-498.

Zamir, L. O., Jung, E. \& Jensen, R. A. (1983). Coaccumulation of prephenate, $L$-arogenate, and spiroarogenate in a mutant of Neurospora. Journal of Biological Chemistry 258, 6492-6496.

ZAMIR, L. O., TIBERIO, R., Fiske, M., BerRy, A. \& JENSEN, R. A. (1985). Enzymatic and nonenzymatic dehydration reactions of L-arogenate. Biochemistry 24, 1607-1612. 